\title{
PROJETO EDITORIAL DO CATÁLOGO BIBLIOGRÁFICO DA BIBLIOTECA DE GERARDO MOURÃO
}

\author{
N. F. Costa' ${ }^{1}$ R. C. Arnaud \& C. B. $\operatorname{Barros}^{3}$
}

'Graduando em Design pela Universidade Federal do Ceará (UFC). E-mail: neiltonfeliciano@ gmail.com; ${ }^{2}$ Graduanda em Design pela

Universidade Federal do Ceará (UFC). E-mail: rebeccaarnaud@ hotmail.com; ${ }_{i}^{3}$ Doutora em Comunicação e Semiótica pela PUC-SP. Professora do curso de Design da Universidade Federal do Ceará. E-mail: camilafb@gmail.com

Artigo submetido em Setembro/2017 e aceito em Novembro/2017

\section{RESUMO}

A ação de extensão objeto deste estudo contempla a elaboração do projeto gráfico para um catálogo bibliográfico de livros doados pela família de Gerardo Mourão à Universidade Federal do Ceará. Essa ação é uma das atividades desenvolvidas pelo Escritório Modelo do curso de Design da UFC em 2017. Em vida, o escritor cearense Gerardo Mourão, famoso na literatura nacional por obras como $O$ valete de Espadas e $O$ país dos Mourões, organizou uma biblioteca de 13.000 títulos doadas pela família à biblioteca universitária. Como forma de organizar e divulgar tal acervo fez-se necessário a projetação de um catálogo bibliográfico, fazendo uso de recursos técnicos gráfico-compositivos propostos pelo campo do Design. Tratando sobre a metodologia de projeto de design, adotamos a proposta do italiano Bruno Munari (2002) e estamos agora em fase de experimentação gráfica, com esboços do projeto editorial. $\mathrm{O}$ projeto tem data de conclusão determinada para o final do semestre 2017.2.

PALAVRAS-CHAVE: Design. Projeto Editorial. Catálogo. Escritório Modelo.

\section{EDITORIAL PROJECT OF THE BIBLIOGRAPHIC CATALOG OF THE GERARDO MOURÃO LIBRARY}

\begin{abstract}
The extension project studied in this article contemplates the elaboration of the graphic project for a bibliographic catalog of books donated by the family of Gerardo Mourão to the Federal University of Ceará. In life, the writer Gerardo Mourão, famous in national literature for works such as $O$ valete de Espadas and $O$ país dos Mourões, organized a library of 13,000 titles. As a way of organizing and disseminating such a collection, it was necessary to
\end{abstract}

design a bibliographic catalog, making use of graphic-compositional technical resources proposed by the field of Design. In dealing with the design methodology, we adopted the proposal of Bruno Munari (2002) and we are now in the stage of graphic experimentation, with sketches of the editorial project. The project is due by the end of the semester 2017.2.

KEYWORDS: Design. Editorial Design. Catalog. Model Office

\section{INTRODUÇÃO}


Em 2014, a Biblioteca Universitária da Universidade Federal do Ceará recebeu em doação da Família do escritor Gerardo Mello Mourão, após seu falecimento e de sua esposa D. Lea de Barros Carvalho e Mello Mourão, um acervo de publicações que constituíam a biblioteca particular do escritor. Esse acervo conta com cerca de 13.000 títulos e incluem 9.763 livros, além de folhetos, catálogos, periódicos, originais de livros e dissertações.

Gerardo Mello Mourão foi poeta, jornalista, filósofo e advogado cearense, nascido em Ipueiras, e reconhecido como um dos grandes intelectuais do país. Dentro da sua vasta produção literária constam títulos de grande importância à literatura brasileira como $A$ invenção do saber (1983), Os peãs (1986), Invenção do mar (1997) e O Valete de espadas (2007). Morreu, aos 90 anos, em 2007 e deixou como legado uma rica obra poética e intelectual, onde cantou as tradições de seu povo, sertanejos e nordestinos, e bebeu nas fontes de clássicos para reconstruir em forma épica a saga de construção das terras brasileiras (Silva, 2010). O reconhecimento de sua produção foi traduzido na conquista do prêmio Jabuti em 1999, uma candidatura a uma cadeira na Academia Brasileira de Letras, além de uma indicação ao prêmio Nobel de Literatura em 1979.

A biblioteca particular do poeta, instalada num apartamento em Copacabana, foi doada à Universidade após a morte de sua esposa em 2011. Como forma de organizar e divulgar esse acervo de 13.000 títulos recém incorporados à Biblioteca Universitária surgiu a demanda de projetar uma publicação contendo a catalogação dos títulos pertencentes à coleção. Essa tarefa foi confiada ao Escritório Modelo do Curso de Design da Universidade Federal do Ceará, passando a ser uma de suas ações de extensão no ano de 2017.

O projeto de editoração do Catálogo D. Lea e Gerardo Mello Mourão tem por objetivo, portanto, a produção de uma publicação que, fazendo uso de técnicas e conceitos oriundos da área de atuação do Design Editorial, possa traduzir em seus elementos gráficos a identidade e obra de Gerardo Mello Mourão e ter, em suas escolhas específicas de grades de construção, tipografia, relações de tamanho de página, margens e hierarquia de informações, um cuidado estético-funcional, permitindo a construção de um livro agradável à leitura e coerente em seus elementos editoriais.

Como base teórica do projeto, além dos conhecimentos projetuais pertencentes ao campo do Design, foi feita uma pesquisa documental e análise da identidade de Gerardo 
Mello Mourão e suas obras, de forma a balizar as escolhas gráficas a serem empregadas na publicação. Acredita-se, dessa forma, ser possível homenagear o doador do acervo e vinculálo, como é de direito, à história dos livros que reuniu em vida.

\section{PROJETO GRÁFICO DO LIVRO IMPRESSO}

Uma das etapas principais do escopo de desenvolvimento de uma publicação é a de criação de seu projeto gráfico. A conclusão dessa etapa permitirá antever a aparência geral que terá a obra após publicada. Ao projeto gráfico compete a construção de um conceito gráfico que norteará a escolha de todos os demais elementos que darão forma e estrutura ao conteúdo do livro final. O bom resultado desse processo se traduz em um livro de agradável leitura e coeso nas suas escolhas gráficas.

A escolha correta do papel que irá suportar o conteúdo, a tipografia melhor adaptada ao tipo de publicação, a quantidade de páginas, as relações espaciais de margens, tamanho de página e distribuição de conteúdo serão, portanto, matérias para o projeto gráfico, sendo grandes responsáveis por guiar o foco de atenção do leitor na medida em que tragam ritmo, organizem hierarquias, facilitem a leitura da obra final e trabalhem a relação texto e imagem na construção semântica do conteúdo.

Quanto à estrutura, é interessante a divisão que faz Araújo (2008) das partes que constituem o livro: elementos pré-textuais, elementos textuais, elementos pós-textuais e elementos extratextuais. Por elementos pré-textuais, entende toda informação acessória que venha antes do conteúdo propriamente dito da obra (prefácio, sumário, introdução...). Os elementos pós-textuais são as informações que se colocam após o texto (índices, bibliografia, colofão...). O elemento textual compreende o corpo de texto que se manterá regular até o fim da publicação, sendo tarefa do designer projetar um padrão de apresentação que permita a correta leitura do conteúdo até sua conclusão e, por fim, a capa do livro é seu principal elemento extratextual, visto ser a porta de entrada que convida à leitura da publicação.

Ainda conforme Araújo (2008), o papel escolhido tem fundamental importância para o caráter da publicação. Características como cor e espessura são responsáveis por facilitar ou dificultar a leitura dos caracteres empregados. Além disso, uma série de variáveis 
devem ser levadas em conta na escolha de qual papel utilizar, como por exemplo o uso de ilustrações ou a impressão de fotografias.

As dimensões do livro determinarão o seu formato. $O$ formato tem grande relevância dentro de um projeto gráfico porque vai delimitar como o usuário interage com aquele objeto, condicionando um conjunto de reações e respostas que o designer deve estar atento ao fazer escolhas de dimensões. Além disso, o formato também responde a questões fisiológicas do leitor e que devem ser compreendidas para que se gere uma experiência de leitura confortável. Importante ressaltar ainda que, na escolha do formato, devem entra considerações de ordem econômica como, por exemplo, a necessidade de obter um melhor aproveitamento do papel, visto que as folhas industriais são vendidas pelo mercado em medidas padronizadas e é tarefa do designer discutir como melhor tirar proveito dessas limitações (ARAUJO, 2008).

A diagramação do livro conforma toda a estruturação do modelo-padrão de página impressa utilizada no projeto gráfico. Leva em conta diversos elementos, como por exemplo, o grid ou grade utilizada para dispor tudo aquilo que precisa ser incluído na página, desde textos até fotografias ou ilustrações. O grid pode ser definido como um conjunto de linhasguias, geralmente dispostas vertical e horizontalmente, que organizam espaços de inserção de conteúdo (LUPTON; PHILLIPS, 2014). Tem importante atuação na estruturação da página e na manutenção da coesão de todo o projeto gráfico. O grid vai ser muito importante também na criação de uma mancha gráfica, na relação entre espaços vazios e preenchidos que dará ritmo e entonação a toda a obra. Se bem construído, permite a criação de uma estrutura agradável de leitura e auxilia o leitor a navegar com facilidade dentro do conteúdo, encontrando elementos como notas e legendas sem grandes dificuldades (SAMARA, 2007).

Uma das mais difíceis e complexas decisões do projeto gráfico é a escolha da tipografia a ser utilizada. Conforme Araújo (2008), a fonte é um conjunto de símbolos e caracteres desenvolvidos a partir de um desenho único. Cada caractere ou letra individualmente é chamado tipo. A escolha da família tipográfica adequada vai ter grande relevância na legibilidade e leiturabilidade da obra, além de ser capaz de construir sentido a partir de escolhas tipográficas que levem em conta também o conteúdo da publicação. É necessário, portanto, um grande cuidado na escolha da melhor fonte a ser empregada, 
levando-se em conta o caráter da publicação e, tendo em mente que, desde os tipos de metal até as modernas fontes digitais, uma ampla possibilidade de desenhos tipográficos estão disponíveis para a boa escolha do designer.

Todos os elementos citados acima devem ser conjugados num todo uniforme e coeso e constituirão o projeto gráfico da publicação. Ao designer cabe fazer essas escolhas com critério e coerência, sempre atento aos fins desejados da publicação e quais construções de sentido deseja revelar através da obra.

\section{MATERIAIS E MÉTODOS}

Para essa ação, tomaremos dois grandes momentos metodológicos, um inserido ao outro, o primeiro de caráter científico e o segundo projetual. Entendendo que a metodologia científica abrangerá o trabalho como um todo. A fase projetual carecerá uma metodologia própria do campo do Design e adotará etapas para o desenvolvimento prático do produto desenvolvido, no caso desta ação o catálogo do acervo da família de Gerardo Mello Mourão. Em diálogo com Lorgus e Odebrecht (2011), compreendemos que:

Embora a metodologia de desenvolvimento do produto tenha seu foco no momento de desenvolvimento do processo projetual, desenvolve-se amparada na metodologia do trabalho científico, o que significa que obedece, como toda pesquisa/trabalho, aos critérios que a validam cientificamente. (LORGUS e ODEBRECHT, 2011, p. 30).

Como primeiro passo, desenvolvemos um amplo estudo bibliográfico e análise documental de obras e objetos do escritor e de sua família. Foram recolhidos e analisados estudos teóricos da obra de Gerardo Mourão em teses e dissertações, as próprias obras publicadas pelo autor, entrevistas que concedeu em diferentes mídias, discursos de posse e recebimento de honrarias, como o título Doutor Honoris Causa, concedido pela UFC em 1993, além de textos escritos pela família por ocasião da doação do acervo e objetos simbólicos como o ex-libris usado em sua biblioteca particular.

Após o estudo teórico e a análise documental, podemos melhor compreender as peculiaridades dessa personagem e mais profundamente contextualizamos nossa ação, o desenvolvimento do projeto editorial. Assim, buscamos a metodologia do designer italiano Bruno Munari (2002), para construirmos uma base metodológica da prática do projeto em 
design. A metodologia desenvolvida por Munari (2002) é proposta como uma ferramenta de racionalização e clarificação das etapas de criação e busca garantir eficiência e evitar gastos de recursos desnecessários dentro do processo projetual.

O método consiste em 12 etapas. O primeiro passo foi identificar o problema. Após identificado, passamos a defini-lo, ou seja, o problema foi refinado e delimitado, permitindo uma exposição clara da questão a ser trabalhada. Em nosso caso, o problema projetual pode ser traduzido em: Quais os requisitos projetuais necessários para o desenvolvimento do projeto gráfico do catálogo da coleção de Gerardo Mello Mourão? E como subperguntas apontamos para: Qual a estrutura de conteúdo da publicação? Qual o público-alvo? Qual os recursos gráficos serão disponíveis para a impressão e acabamento de tal material? Como representar visualmente as obras e a personalidade do escritor? A partir dessas inquietações, buscamos na pesquisa bibliográfica e documental as informações necessárias para melhor responder nosso problema projetual.

Passamos, então, a investigar e analisar soluções já empregadas em projetos similares para a melhor compreensão do artefato a ser desenhado. Entramos, depois disso, na fase de criatividade, onde as informações recolhidas nas fases anteriores foram sintetizadas num processo criativo. A fase seguinte, de materiais e tecnologias, permitiu a consideração dos aspectos técnicos e materiais disponíveis para a execução do projeto para que depois, na fase de experimentação, coloquemos à prova as várias possibilidades de usos desses recursos. O projeto encontra-se atualmente nessa etapa de experimentação. A partir de todo o estudo prévio, estamos experimentando, nas formas e possibilidades, técnicas e maneiras de melhor executar o projeto gráfico da publicação

Com tudo isso em mãos será possível passar a construção de um modelo de resposta ao problema e sua posterior verificação pelos usuários. Se o protótipo resistir a essa verificação, o projeto está apto a passar a sua última fase, que é a de geração de desenhos construtivos, ou seja, de apresentação da solução final.

\section{RESULTADOS E DISCUSSÕES}

Depois de definido o problema projetual, passamos a decidir conceitualmente 
quais os requisitos necessários ao seu correto desenvolvimento. Chegamos a três prérequisitos fundamentais: clareza na apresentação do conteúdo, fácil navegação e construção de identidade. Por se tratar de uma publicação de caráter técnico bastante pronunciado, envolvendo a organização de 13.000 entradas bibliográficas, concluímos que a apresentação clara, organizada e legível dessas informações era de extrema importância para o sucesso da publicação. Intimamente ligada ao trabalho de organizar uma complexidade de informações, consideramos necessário um projeto visual que facilitasse a navegação do leitor, permitindo que encontrasse rapidamente qualquer título consultado. Abraçando esses dois critérios de funcionalidade, resolvemos, por fim, que as escolhas projetuais deveriam ser guiadas de forma a traduzir a identidade de Gerardo Mello Mourão, em nome de quem, afinal, a família doou o acervo objeto da publicação.

Com esses critérios definidos, passamos a buscar na análise documental realizada sobre a identidade e obra de Gerardo Mello Mourão, aspectos relevantes que pudessem ser usados como nortes na condução do projeto gráfico. Notamos, nessas pesquisas, que, em sua obra, o poeta trazia insistentemente reminiscências da sua infância em Ipueiras, cidade do interior do Ceará, fazendo uso de um amplo leque de referências à cultura e tradições do sertão e do povo nordestino. Como comenta Márcio Catunda (1999, pg.06), “A sua poesia, impregnada da geografia do Nordeste, tem nas imagens do sertão uma lembrança obsessiva." Aliado a isso, observa-se em Gerardo um profundo conhecimento e interesse em autores clássicos, com especial atenção aos gregos. Essa intersecção entre os elementos da sua infância no interior do Ceará, combinada com sua formação classicista, vai marcar grande parte do seu trabalho. Ainda conforme Catunda (1999):

\begin{abstract}
Estas semelhanças entre o mundo grego de suas elucubrações e o universo de sua província natal são pilares com que constrói a sua fábula, vaticinando a grandeza do poetar que funda civilizações. Nesse transporte poético no tempo e no espaço associa as dimensões geográfica e humana das duas regiões do seu imaginário, onde edifica o monumento de sua obra, elaborando a saga brasileira. Quando vê nos cantadores de feira de Ipueiras a imagem de Homeros de eterna verve, constata o quanto é forte o Nordeste brasileiro (CATUNDA, 1999, pg. 10).
\end{abstract}

Resolvemos, portanto, se apropriar desse aspecto da sua obra para balizar a condução de todo o projeto gráfico, que pode assim ser sintetizado na frase de Catunda (1999, pg.06) "Alma grega, raízes nordestinas". Trata-se, portanto, de construir um projeto gráfico que revele em seus elementos estético-formais aspectos da tradição clássica, inserindo, entretanto, 
motivos estranhos a essa tradição, ancorados não mais na Grécia, mas no sertão de Ipueiras da infância de Gerardo.

Como principal elemento de remissão à sua infância em Ipueiras, elegemos trabalhar graficamente a flor de Gitirana. Gerardo conta, em discurso ao aceitar o título de Doutor Honoris Causa pela Universidade Federal do Ceará, que se escondeu, ainda criança, quando a família o quis enviar ao Rio de Janeiro, numa moita de Gitiranas. Desde então, adquiriu uma relação emocional com a pequena flor arroxeada, acostumada ao clima quente e à aridez do sertão de Ipueiras.

\begin{abstract}
Mas no dia em que se marcara a partida, os parentes prontos para o bota-fora na casa amarela da estação de Ipueiras, o menino escapuliu pelo quintal, contemplou a grande cajazeira, os pés de ata, as goiabeiras, os pés de mulungu, de trapiá, de joá, da casa em que nascera, e desapareceu por uma porteira que dava para as barrancas do rio Jatobá. Correu pela beira do rio, com um companheiro solidário, e escondeuse numa profunda moita de mofumbo, entre gitiranas em flor. Até hoje, guardo a paixão pelas gitiranas, e mais tarde aprendi de cor os versos antológicos das gitiranas, de nosso poeta Otacílio Colares. Adquiri o costume de recitá-los nas passagens de minhas estrepolias [...] Alegro-me que os versos sejam também uma lembrança de Otacílio. Mas eles são na verdade uma fidelidade ao país das Ipueiras, no dia em que, por amor às minhas raízes, fiquei protegido entre as flores de mel do mofumbo silvestre e as flores da gitirana, até ouvir o apito do trem que partia. (MOURÃO, 1993)
\end{abstract}

Decidimos, portanto, construir um padrão utilizando a flor de Gitirana como elemento principal, se aproveitando do poder simbólico da pequena flor patente no discurso de Gerardo. A opção por trabalhar padrões se coloca devido a importância que esses motivos decorativos tinham na Grécia antiga, principalmente na decoração de cerâmicas e vasos. Optou-se ainda por construir esse padrão a partir de uma técnica manual, elegendo-se a gravura, pelas suas conexões às tradições de xilogravura tão presentes no sertão nordestino, como meio de se obter os elementos gráficos para o desenvolvimento do padrão. Relevante é o que coloca Bachelard (1991) a respeito da gravura, quando comenta que, dentre as técnicas, essa talvez seja a que mais tem o poder de revelar a luta de matérias patente numa obra, neste caso, a força da mão que rompe com o cinzel a madeira ou o metal em busca de um desenho ainda sem forma. Esse aspecto da força manual, trouxemos para a identidade gráfica do projeto.

Como forma de dar reposta gráfica ao formato de publicação que trabalhávamos, passamos a um estudo de edições semelhantes já publicadas. Nessa fase, pesquisamos 
catálogos bibliográficos, dicionários, enciclopédias e edições bibliográficas. Chegamos, por fim, ao formato de 12,7 x $25.5 \mathrm{~cm}$. Conforme Brighthurst (1999), na renascença, no início da produção seriada de livros e impressos, eram preferidos os formatos de proporções mais verticalizadas. Tencionamos usar dessa verticalização para dar ao projeto gráfico reminiscências de publicações antigas, encerradas como clássicas. Além disso, fizemos uso de largas margens, de ao encontro à antiga tradição de margens generosas, sendo prova o grande uso das proporções áureas em publicações durante a renascença. O uso de margens externas largas permitiu também a projetação de um sistema de navegação, baseado no sistema de classificação decimal de Dewey, usado pelas bibliotecas da UFC para catalogar seus acervos, que permite ao leitor se localizar através dos campos do conhecimento e facilmente encontrar o título que procura.

Dentro das considerações tipográficas, a fonte Sabon, projetada por Jan Tschichold entre os anos de 1964 e 1967, a partir do trabalho de Claude Garamond e Robert Granjon, foi escolhida para compor o projeto editorial da publicação. A decisão foi tomada levando-se em consideração o caráter histórico do desenho, aliado à sua economicidade, visto Tschichold, atraiçoando sua formação moderna, ter chegado a um desenho $15 \%$ menos largo que suas referências renascentistas. Além disso a fonte permite o uso de quatro pesos distintos, sem contar a disponibilidade de versaletes, o que é importante para gerar hierarquia dentro de uma publicação complexa em informações. Foi considerado também a quantidade e qualidades de caracteres disponíveis, visto o acervo contar com entradas bibliográficas em diferentes línguas e que requerem um uso relativamente amplo de diacríticos.

Após construídos os elementos de estruturação da página-padrão, passamos a considerar quais recursos de impressão e acabamento são possíveis ser requisitados para a execução do projeto. O catálogo será impresso pela Imprensa Universitária da Universidade Federal do Ceará. Pela fácil disponibilidade, escolhemos o papel pólen $80 \mathrm{~g} / \mathrm{m}^{2}$ para compor o miolo da publicação. O papel de cor levemente amarelada traz, além disso, conforto visual ao leitor. A capa foi projetada para ser impressa em tecido através do processo de serigrafia. $\mathrm{O}$ tecido é incorporado por colagem à capa de papel cartão e o acabamento é refinado fazendose uso da folha de guarda.

O projeto encontra-se agora na fase de experimentação. Passamos, dessa forma, a 
gravar em placas de linóleo os desenhos da flor de gitirana. A partir dessas gravuras, será possível elaborar um padrão a ser empregado na capa da publicação. Todas as relações de dimensões, margens, elementos gráficos e tipografia estão sendo também experimentadas, de forma a se chegar ao melhor resultado possível em termos de legibilidade e coerência formal. Depois dessa fase, será possível imprimir uma edição de teste, disponibilizada aos usuários potenciais para eventual apontamento de falhas técnicas ou conceituais. Superada essa fase, o catálogo estará pronto para publicação.

\section{CONSIDERAÇÕES FINAIS}

O projeto tem demonstrado a quantidade e complexidade de elementos que envolve o projeto gráfico de uma única publicação. Articular questões técnicas, relativas a leiturabilidade e ergonomia do objeto, a questões simbólicas, envolvendo a tradução, por exemplo, de identidades em elementos gráficos, nos mostra a relevância do profissional de design e a necessidade que se faz mister das suas categorias conceituais na execução de projetos editoriais e publicação de impressos.

\section{REFERÊNCIAS}

ARAÚJO, E. A Construção do Livro. Rio de Janeiro: Lexicon Editora Digital, 2008.

BACHELARD, G. O direito de sonhar. Rio de Janeiro: Bertrand Brasil, 1991.

BRINGHURST, R. The elements of typographic style. Vancouver: Hartley \& Marks Publishers, 1999.

CATUNDA, M. Na trilha dos eleitos, vol. I. Rio de Janeiro: Espaço e Tempo, 199.

LORGUS, A. L.; ODEBRECHT, C. Metodologia de pesquisa aplicada ao design. Santa. Catarina: Edifurb, 2011.

LUPTON, E; PHILliPS, J. C. Novos fundamentos do design. São Paulo: Cosac Naify, 2014.

MOURÃO, G.M. Discurso ao Receber o grau de Doutor Honoris Causa na Universidade Federal do Ceará. Disponível em " $h t t p: / / w w w . j o r n a l d e p o e s i a . j o r . b r / m e l l o 05$. Acesso em 18 
de set. de 2017.

MUNARI, B. Das coisas nascem coisas. São Paulo: Martins Fontes, 2002.

SAMARA, T. Grid: construção e desconstrução. São. Paulo: Cosac Naify, 2007.

SILVA, E.O. Gerardo Mello Mourão e a gênese épica de Invenção do Mar. 2010. 125f. Dissertação (Mestrado em Literatura). Programa de Pós-Graduação em literatura e diversidade cultural, Universidade Estadual de Feira de Santana. Feira de Santana, 2010. 